\title{
Mechanism of the inverted supinator reflex
}

\author{
A clinical and neurophysiological study
}

\author{
B. V. ESTANOL AND O. S. M. MARIN \\ From the Departments of Neurology, Johns Hopkins University, School of Medicine \\ and Baltimore City Hospitals, Baltimore, Maryland, USA
}

SYNOPSIS The inverted supinator reflex sign was analysed in two patients by recording the response of the finger flexor muscles of the forearm to tapping of the styloid process of the radius before and after procaine infiltration of these muscles. It was found that the response persisted despite the block. The findings support the concept that the underlying mechanism is increased alpha motoneurone excitability below the level of the lesion; however, a possible contribution of the dynamic muscle spindles could not be excluded.

The inverted supinator (brachioradialis) reflex is a sign that was introduced into clinical medicine by Babinski (1910). Since that time, it has been widely accepted as signifying a lesion at the C5-C6 spinal cord segments. There are two components of this abnormal reflex: (1) an absence of contraction of the brachioradialis muscle when the styloid process of the radius is tapped, and (2) a hyperactive response of the finger flexor muscles; a response that is subserved by a lower spinal cord segment (C8). It was classically believed that this clinical phenomenon could be readily explained by a lesion at C5-C6 cord levels impairing the segments directly responsible for the brachioradialis reflex, and that the hyperactivity of the finger flexors was due to reflex irradiation to a lower level by a central mechanism (Babinski, 1910; Dejerine, 1926). Walshe (1963), while confirming the frequency of this reflex 'inversion' in cases of grey matter lesions of the 5th and 6th cervical segments, considered that the phenomenon was due to the emergence of an alternative motor response or, as it were, a replacement of one reflex by another. The mechanism, he suggested, would be central. Wartenberg (1944) insisted that in normal subjects or in cases of hyperexcitability of reflexes not necessarily associated

(Accepted 19 April 1976.) with structural lesions of the central nervous system, a single tap on the lower third of the radius could give rise to a multiplicity of motor responses. He believed that the inversion of the supinator reflex did not necessarily indicate spinal cord damage and that it could reflect instead a peripheral nerve lesion. The inversion would represent the modification of the usual pattern of motor responses by the dissociation of its various components. The central mechanism for the inversion has recently been challenged by some authors (Lance, 1965; Lance and de Gail, 1965; Teasdall and Magladery, 1974) who have proposed that irradiation of myotatic reflexes is not secondary to intraspinal spread but is due instead to a 'peripheral' mechanism. This has been postulated to be the stimulation of spindles of the muscles involved due to heightened sensitivity of the spindles (Lance, 1965; Lance and de Gail, 1965). An alternative explanation, proposed by several authors (Dietrichson, 1971; Landau and Clare, 1964), is that an increase in alpha motoneurone excitability exists in spasticity, and this may also explain this phenomenon. Recently, Dietrichson showed that the hyperactive ankle jerk of spastic subjects is due to both hypersensitivity of the spindles and an increase in alpha motoneurone excitability (Dietrichson, 1971). In the light of the 'peripheral' hypothesis the contraction of the finger flexors will be due to 
stimulation of the spindles of the finger flexor muscles, given to the positive bias of the gamma system of these muscles.

The fact that both alpha and gamma motoneurones in normal circumstances are activated simultaneously (coactivation) (Hagbarth and Vallbo, 1968) makes it unlikely that only one mechanism would be operating. Because a systematic investigation of the behaviour of finger flexor muscles in patients with inverted supinator reflex has never been undertaken, it was believed that infiltration of the finger flexor muscles with procaine, in order to block the muscle spindles (Matthews and Rushworth, 1957; Gassel and Diamantopoulos, 1964) and hence to block the afferent volleys coming from them, could give some insight into whether a peripheral or central mechanism was operating. Thus, if tapping the styloid process after blockage with procaine of these muscles would not elicit a response, that would argue for a peripheral mechanism. If, on the other hand, the contraction of the finger flexor group was present in response to the same blow, but a direct finger jerk response was absent, that would favour an increased excitability of the alpha motoneurone.

\section{METHODS}

Two patients with inverted supinator reflexes on the basis of spondylotic myelopathy were selected purely on that ground. There was no history of pain or sensory complaints, nor were there any abnormal sensory findings on physical examination. The diagnosis was made on clinical and myelographic grounds. An electromyograph was set up so that tapping of the styloid process of the radius or the fingers would trigger the sweep of the oscilloscope. A single channel oscilloscope was used and the muscle's responses were recorded with concentric needle electrodes. An earth (ground) electrode was placed between the recording electrode and the site of tapping. Shortest latencies were used, or several responses were superimposed and an average latency was obtained. The responses were recorded on magnetic tape and photographed with a Polaroid camera. Video tapes of the responses were also made. The recording electrodes were placed in the bulk of the brachioradialis and of finger flexor groups of the forearm, $8 \mathrm{~cm}$ from the lateral and medial condyles. Procaine $1 \%$ was used to infiltrate the finger flexor muscle group of one arm. Approximately $15 \mathrm{ml}$ were injected in both patients. This effectively abolished the direct finger jerk, leaving motor strength of finger flexion unimpaired. Direct stimulation of the ulnar and median nerves above the elbow induced contraction of the finger flexor muscle group, proving that the efferent connexions were patent. Absence of contraction in this muscle group to tapping of the fingers was recorded also on video tape. The experiments were repeated three to four times during the same session.

\section{RESULTS}

Recording from brachioradialis and finger flexor muscles proved that brachioradialis responses were absent on direct tapping of the styloid process. The latency of finger flexor muscles was $26.8 \mathrm{~ms}$. Tapping the fingers (before the infiltration with procaine) elicited a response with a latency of $31.2 \mathrm{~ms}$ in the finger flexor group (Fig. 1). After infiltration with procaine, clinical testing revealed that muscle strength was subjectively and objectively the same as before the injection. Finger jerks in the infiltrated hand were absent. However, tapping the styloid process elicited a response in the finger flexor muscles. The latency of this response after the infiltration was the same as before the injection $(26.9 \mathrm{~ms})$ (Fig. 2).

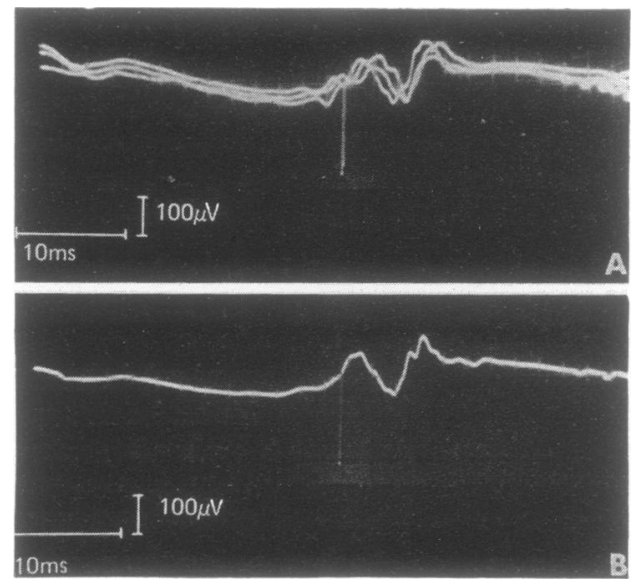

FIG. 1 A. Tapping the styloid process of the radius before infiltration. B. After infiltration of the flexor muscles of the forearm with procaine $1 \%$, tapping elicited a response in these muscles with the same latency of $26.8 \mathrm{~ms}$. (Calibration $10 \mathrm{~ms}, 100 \mu \mathrm{V}$.) 

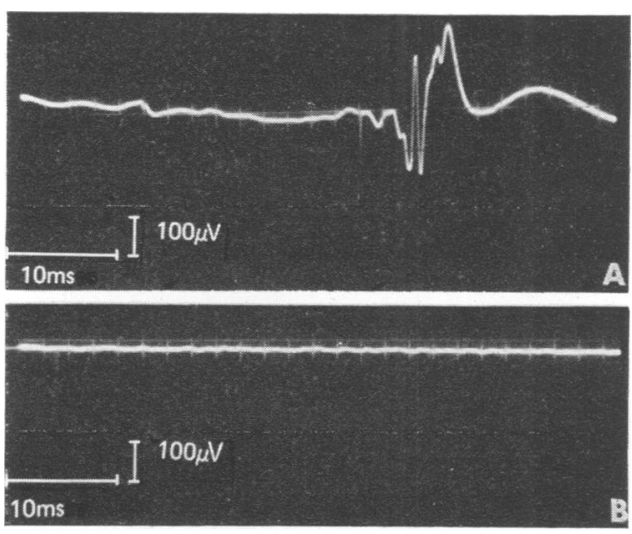

FIG. 2. A. Tapping fingers before infiltration of the finger flexor muscles of the forearm with procaine $1 \%$ elicited a response in the same muscles with a latency of $31.2 \mathrm{~ms}$. B. After infiltration no response was elicited.

\section{DISCUSSION}

We owe to Sherrington the two possible conceptual explanations of this abnormal reflex. In 1898 he found that the crossed knee jerk and crossed abductor reflex persisted after a midline longitudinal section of the spinal cord. Hence, transmission from one side of the cord to the other of an impulse from the periphery was blocked and a peripheral mechanism for the crossed reflex phenomenon was postulated. He proposed that transmission of mechanical vibration to the muscles was responsible for the contralateral reflexes (Sherrington, 1898). On the other hand, the concept of irradiation as a central phenomenon is fundamental to Sherringtonian physiology (Sherrington, 1926), although admittedly he never applied this concept to explain the mechanism of contraction of relatively distant muscles with hyperactive myotatic reflexes.

It has been suggested in the recent literature (Lance, 1965; Lance and de Gail, 1965; Teasdall and Magladery, 1974) that the inverted supinator reflex could be best explained in terms of a peripheral mechanism; however, this thesis in this particular instance has not been proved experimentally. On the other hand, Landau and Clare (1964) found that electrically and mechanically induced reflexes on the spastic side were increased to the same extent, indicating both an increased sensitivity of the dynamic spindles and an increased excitability of the alpha motoneurones. More recently, Dietrichson (1971) was able to prove, using mechanically and electrically induced reflexes, that both mechanisms are very clearly operating. The absence of a direct finger flexor myotatic response at a time when finger flexion could be elicited by a blow on the styloid process is evidence against stimulation of the spindles of the finger flexor group. It has recently been shown (Teasdall and Magladery, 1974) that, in spastic subjects, the $H$ reflex latencies of the forearm flexors and brachioradialis are the same. It was also found that the latencies of both reflexes when a tap was applied to the styloid process were similarly equal. This has been adduced to support the hypothesis that these reflexes result from an independent simultaneous myotatic mechanism and not from intra-spinal spread. However, this was not borne out by our experiments. It is, nevertheless, entirely possible that in the normal clinical situation there is a contribution of the dynamic muscle spindles. We were not able to rule out this contribution in our experiments.

An important point that arises from these experiments is the question of the location of the lesion in these cases. If we accept the hypothesis of the 'peripheral irradiation', the abnormal reflex can be easily explained by postulating a lesion at the level of the afferent root. On the other hand, if the essential mechanism is central intra-cord spread with enhanced alpha motoneurone excitability, the lesion must be on the efferent side, either at the alpha motoneurone at C5-C6 level or to motor root compression of the same spinal cord segment. Perhaps electrical studies can throw further light on this problem.

Our findings support the idea that the mechanism of the inverted supinator reflex is intraspinal spread made possible by an increased excitability of the alpha motoneurone at levels below the lesion and damage of the alpha motoneurones or motor roots at C5-C6 levels.

\section{REFERENCES}

Babinski, J. (1910). Inversion du réflexe du radius. Bulletin et Mémoires de la Société de Médecine des Hôpitaux de Paris, 30, 185-186.

Dejerine, J. (1926). Sémiologie des Affections du System Nerveux. Masson et cir. Editeurs, Paris. 
Dietrichson, P. (1971). Phasic ankle reflex in spasticity and Parkinsonian rigidity. Acta Neurologica Scandinavica, 47, 22-51.

Gassel, M. M., and Diamantopoulos, E. (1964). The effect of procaine nerve block on neuromuscular reflex regulation in man. An appraisal of the role of the fusimotor system. Brain, 87, 729-742.

Hagbarth, K. E., and Vallbo, Å. B. (1968). Discharge characteristics of human muscle afferents during muscle stretch and contraction. Experimental Neurology, 22, 674-694.

Lance, J. W. (1965). The mechanism of reflex irradiation. Proceedings of the Australian Association of Neurology, 3, 77-81.

Lance, J. W., and de Gail, P. (1965). The spread of phasic muscle reflexes in normal and spastic subjects. Journal of Neurology, Neurosurgery, and Psychiatry, 28, 328334.

Landau, W., and Clare, M. H. (1964). Fusimotor function. Part 4. Reinforcement of the $\mathrm{H}$ reflex in normal subjects. Archives of Neurology (Chic.), 10, 117-122.
Matthews, P. B. C., and Rushworth, G. (1957). The selective effect of procaine on the stretch reflex and tendon jerk of soleus muscle when applied to its nerve. Journal of Physiology, 135, 245-262.

Sherrington, C. S. (1898). Philosophical Transactions 190B. Reprinted in Selected Writings of Sir Charles Sherrington, p. 152, 1939. Edited by D. Denny Brown. Hamish Hamilton: London.

Sherrington, C. S. (1926). The Integrative Action of the Nervous System. Yale University Press: New Haven.

Teasdall, R. D., and Magladery, J. W. (1974). Brachioradialis reflex and contraction of forearm flexors. Archives of Neurology (Chic.), 30, 94-95.

Walshe, F. M. R. (1963). Diseases of the Nervous System. 10th edn. Livingstone: Edinburgh.

Wartenterg, R. (1944). Studies of reflex. History, physiology, synthesis and nomenclature: study 2 . Archives of Neurology and Psychiatry (Chic.), 52, 341-358. 